\title{
An Overview of Bearing Candidates for the Next Generation of Reusable Liquid Rocket Turbopumps
}

\author{
Jimin $\mathrm{Xu}^{1 *}\left(\mathbb{C}\right.$, Changhuan $\mathrm{Li}^{2}$, Xusheng Miao ${ }^{2,3}$, Cuiping Zhang ${ }^{4}$ and Xiaoyang Yuan ${ }^{5}$
}

\begin{abstract}
There is a consensus in the aerospace field that the development of reusable liquid rockets can effectively reduce the launch expense. The pursuit of a long service life and reutilization highly depends on the bearing components. However, the rolling element bearings (REBs) used in the existing rocket turbopumps present obvious and increasing limitations due to their mechanical contacting mode. For REBs, high rotational speed and long service life are two performance indexes that mutually restrict each other. To go beyond the DN value (the product of the bearing bore and rotational speed) limit of REBs, the major space powers have conducted substantial explorations on the use of new types of bearings to replace the REB. This review discusses, first, the crucial role of bearings in rocket turbopumps and the related structural improvements of REBs. Then, with the prospect of application to the next generation of reusable liquid rocket turbopumps, the bearing candidates investigated by major space powers are summarized comprehensively. These promising alternatives to REBs include fluid-film, foil, and magnetic bearings, together with the novel superconducting compound bearings recently proposed by our team. Our more than ten years of relevant research on fluid-film and magnetic bearings are also introduced. This review is meaningful for the development of long-life and highly reliable bearings to be used in future reusable rocket turbopumps.
\end{abstract}

Keywords: Aerospace, Reusable liquid rocket turbopumps, Rolling element bearings, Bearing candidates, Review

\section{Introduction}

As the most important equipment supporting humans in their exploration of the vast universe, liquid propulsion rockets play an indispensable role in the establishment of satellite navigation systems, construction of space stations, manned lunar landing missions and other challenging space activities $[1,2]$. The costs of research and development of liquid propulsion rockets are so high that few countries can afford them. Generally, most rockets are of the one-off type and are totally discarded after the completion of a launch task. With the remarkable growth in launch payloads and launch frequency, the launch cost is progressively becoming a challenging issue

\footnotetext{
*Correspondence: xujimin2017@hfut.edu.cn

${ }^{1}$ Institute of Tribology, School of Mechanical Engineering, Hefei University of Technology, Hefei 230009, China

Full list of author information is available at the end of the article
}

among the major space powers, and significant attention has been paid to the reduction of that cost. The current compromise approach is the widespread use of mature rocket products, which undoubtedly restricts further improvement of aerospace technologies. There is already a worldwide agreement that the reusable rocket is the most promising approach to cut down the launch cost $[3,4]$. It is well known that the NASA space shuttle was the first-generation of reusable launch vehicles in human history. Its initial design objectives were to decrease the launch cost to thirty million dollars per time and compress the launch interval to 1-2 weeks [5]. However, the actual effects were far from the anticipations. The real cost of each launch was at least half a billion dollars and the launch preparation time extended to 2-3 months. In addition, fourteen astronauts lost their lives during the 135 launch tasks. The biggest problem of the space shuttle was the long-duration maintenance, which wasted a 
great amount of manpower and material resources. To ensure the system safety and reliability, numerous components had to be replaced [6]. The extra disassembly procedures made such maintenance very complicated, and NASA finally abandoned the space shuttle project in 2011 [7]. After that, the research focus has been transferred to the reusable liquid rocket, and some remarkable achievements have been attained. The current research goal is to reuse the first stage of the launched rocket successfully. Figure 1 displays the overall recycling scheme of the first stage on the drone ship after stage separation and attitude adjustment. In 2015, Space X, a private American aerospace manufacturer and space transportation services company, successfully accomplished the recovery and reutilization of the first stage of its Falcon 9 rocket [8]. This sparked a boom in the development of reusable liquid rockets worldwide, and the major space powers have been engaged in similar projects. At the beginning of 2018, Space X launched the Falcon Heavy rocket and achieved the recovery of its two boosters simultaneously [9]. As the most powerful rocket in service, the payload capacity of the Falcon Heavy rocket is approximately 2.5 times that of the Chinese Long March 5 rocket. The magnificent feat of the recovery of multiple boosters was a new historical record. However, a thorough overhaul and maintenance is indispensable for the reutilization of Falcon rockets, which is attributed to the inherent structural features of the existing liquid rocket turbopump [10].

The turbopump system is the heart of a liquid rocket and is used for the pressurization of the fuel and oxidizer $[11,12]$. It consists of many rotating components, such as the bearings, seals, balance disc, impellers and inducer. Owing to the requirement of lower weight, the turbopump system is usually designed near the limits

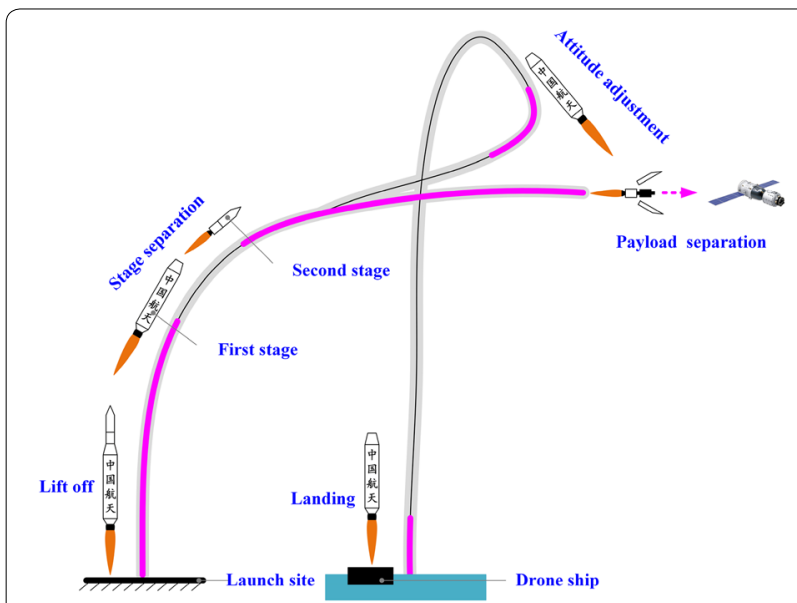

Figure 1 Overall recycling scheme of the first stage of the launched rocket of the state of the art. The vice president of the Chinese Academy of Aerospace Propulsion Technology pointed out that the most important component for developing a real reusable liquid rocket turbopump was the bearing [13]. Until now, all the launched liquid rocket turbopumps have adopted rolling element bearings (REBs) to support their high-speed rotors. Such bearings transmit external loads by a mechanical contact with point or line form, which would result in a phenomenon of severe stress concentration. Taking the bearing of the Japanese LE-7 rocket turbopump as an example, the maximum contact stresses at the inner and outer raceways are approximately $1.54 \mathrm{GPa}$ and $1.63 \mathrm{GPa}$, respectively [14]. Additionally, the rollers and raceways are under a mixed friction state, instead of an elastohydrodynamic lubrication state, due to the ultra-low viscosity of liquid oxygen $\left(\mathrm{LO}_{2}\right)$ and liquid hydrogen $\left(\mathrm{LH}_{2}\right)$. The wear degree of the bearings is quite noticeable and will be significantly enhanced with the increase in rotational speed. However, higher rotational speed of the turbopump for accelerating the supply rate of the fuel and oxidizer is the key index for developing the future heavy rockets [15]. The limitations of REBs in existing rocket turbopumps are increasingly prominent and have constrained the development of advanced rocket engines. As the failure of a REB could cause fatal accidents, the major space powers have conducted substantial explorations of new types of bearings to replace the REB [16]. A representative example is the proposal of Prof. Childs, from Texas A\&M University, of a hybrid fluid-film bearing scheme for the next generation of reusable liquid rocket turbopump in the USA [17].

Studies of alternatives to the REB have been conducted for several decades. The bearing candidates differ in structures and operational principles. Frustratingly, the existing rocket turbopumps still use REBs instead of these new types of bearings. The desirable breakthrough from the laboratory environment to practical service needs not only exceptional courage but also clear and comprehensive consideration of the previous studies. The merits and demerits of these bearing candidates must be fully analyzed to explore a feasible application scheme. This review analyzes, first, the crucial role of REBs in turbopump systems and their structural improvements. With the prospect of application to the next generation of reusable liquid rocket turbopumps, a detailed summary of the alternatives to the REB is provided, which include the fluid-film, foil and magnetic bearings. Specially, a novel superconducting compound bearing with a superconducting magnetic force and a hydrodynamic fluidfilm force, recently proposed by our team, is emphatically introduced. Finally, a brief consideration about the feasible research and application scheme to the aerospace field is discussed based on the state of the art. 


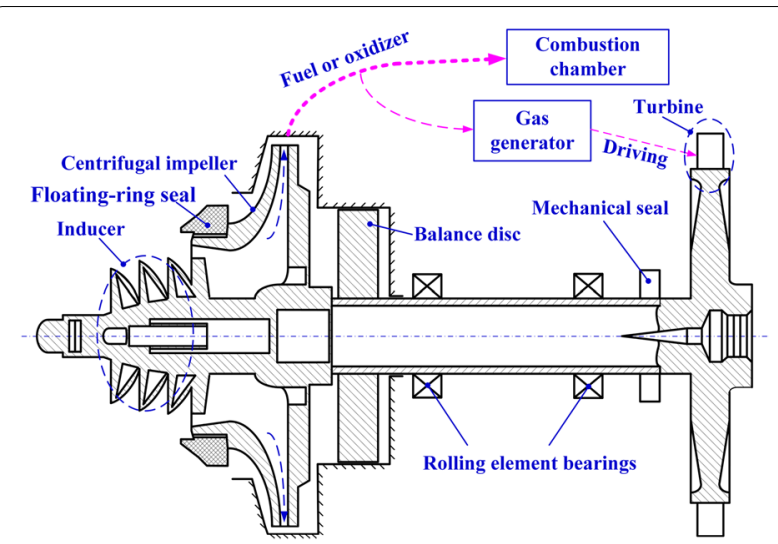

Figure 2 Typical structure of the liquid rocket turbopump rotor system

\section{Current Status of REBs in Rocket Turbopumps}

\subsection{The Role of REBs}

In the entire field of rotating machinery, the rocket turbopump system has the highest power-to-weight ratio and the improvement of power is primarily achieved by increasing the rotational speed [18]. Figure 2 illustrates a typical structure of the turbopump rotor system, which consists of the inducer, floating-ring seal, centrifugal impeller, balance disc, REBs, mechanical seal, turbine and other components. The two REBs are in an inboard arrangement, which means that the centrifugal impeller and the turbine are of the overhung type [19]. Except the radial load, the REBs have to cooperate with the balance disc to overcome the axial load. The increase in rotational speed will generate a larger impeller force and the REBs will be subjected to more severe working conditions. Usually, researchers use the DN value limit to characterize the work capacity of REBs [20]. This index is the product of the bearing bore $D(\mathrm{~mm})$ and rotational speed $N(\mathrm{r} / \mathrm{min})$. Under the current status of bearing materials, the DN limit of REBs is below $3 \times 10^{6} \mathrm{~mm} \cdot \mathrm{r} / \mathrm{min}$ [21]. According to statistical analyses, the main failure mode of REBs under poor lubrication is abrasion instead of fatigue [22]. If the DN limit is exceeded, lubrication will deteriorate significantly. The concomitant overheating and mechanical wear may even lead to the sudden failure of REBs. In rocket turbopumps, another common failure mode of REBs is the breakdown of the rollers and retainer caused by the impact load [23]. Especially at the start-up stage, the sudden increase in loads makes that REBs easily present such failure. The acceleration time from zero to the working speed (usually $10000-60000 \mathrm{r} / \mathrm{min}$ ) is of only a few seconds and the impeller force increases rapidly. Therefore, except for abrasion failure, the increase in working speed will also aggravate the probability of breakdown failure. There is a grievous conflict between the improvement in turbopump power and the life limitation of rolling bearings, which has constrained the development of future advanced rocket engines.

The reliability and service life of REBs are vital to the whole rocket. REBs must undergo harsh experiments before practical service. Compared to the static ignition test [24], namely the ignition test of the turbopump system on the ground experimental platform, the assessment test in the laboratory environment is more economical. Figure 3 displays an experimental device developed by our team [25], which is used for testing the REBs used in $\mathrm{LO}_{2}$ turbopumps. Liquid nitrogen is used to simulate the low-temperature and low-viscosity characteristics of $\mathrm{LO}_{2}$. The driving turbine can realize a maximum rotational speed of $50000 \mathrm{r} / \mathrm{min}$. Axial and radial loads can be applied to the testing bearings. This device is an important tool to investigate the start-up characteristics and fatigue life of turbopump REBs.

\subsection{Structural Improvements of REBs}

As a type of mature industrial product with a long history [26], REBs have proved their reliability under the most diverse operational conditions [27, 28]. The typical REBs consist of rollers, inner ring, outer ring and retainer. Thanks to the urgent demands of high speed and

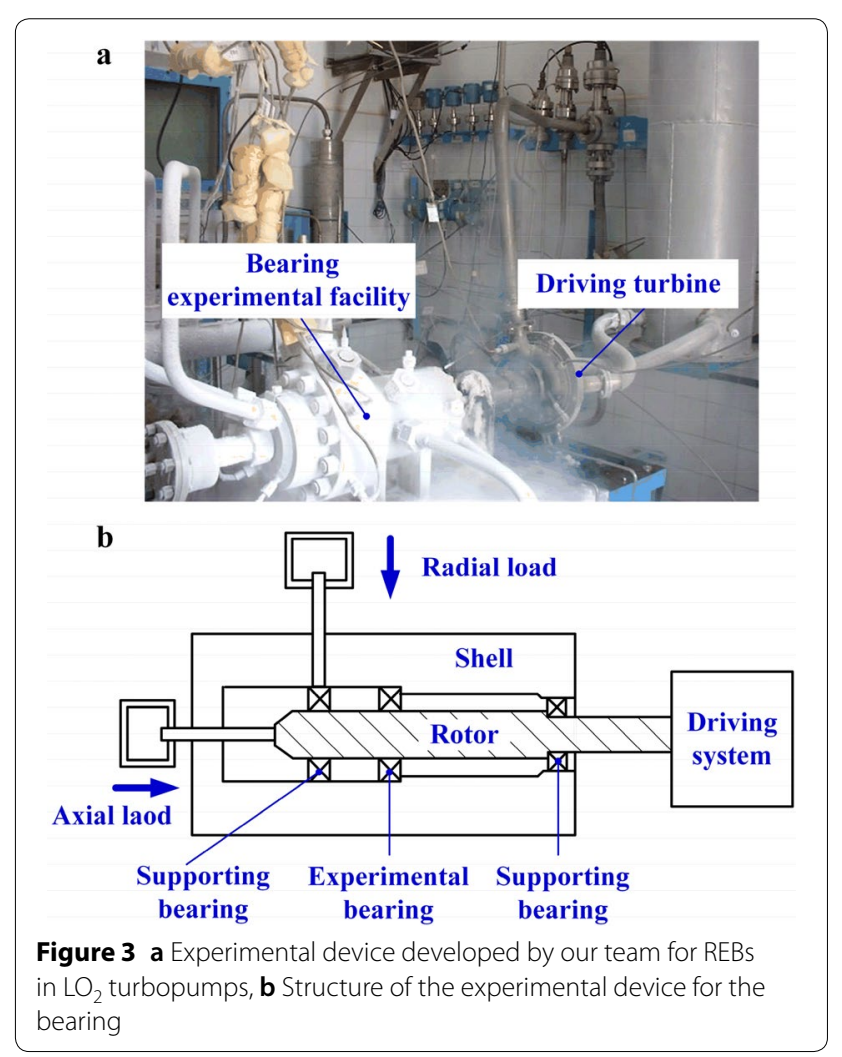




\begin{tabular}{llll}
$\begin{array}{l}\text { Table } \mathbf{1} \text { Mechanical } \\
\text { and common bearing steels }\end{array}$ & $\begin{array}{c}\text { performance } \\
\text { and }\end{array}$ & $\mathbf{S i}_{\mathbf{3}} \mathbf{N}_{\mathbf{4}}$ & ceramic \\
\hline Item & $\mathrm{Si}_{\mathbf{3}} \mathbf{N}_{\mathbf{4}}$ & $\mathrm{GCr} \mathbf{1 5}$ & $\mathbf{M 5 0}$ \\
\hline Density $\left(\mathrm{kg} / \mathrm{m}^{3}\right)$ & 3200 & 7830 & 7972 \\
Young modulus $(\mathrm{GPa})$ & 310 & 219 & 218 \\
Hardness HRC & 7090 & 64 & 66 \\
$\begin{array}{l}\text { Coefficient of thermal } \\
\text { expansion }(\mathrm{m} / \mathrm{K})\end{array}$ & $2.9 \times 10^{-6}$ & $12.3 \times 10^{-6}$ & $12.1 \times 10^{-6}$ \\
Corrosion-proof & Superior & Weak & Weak \\
\hline
\end{tabular}

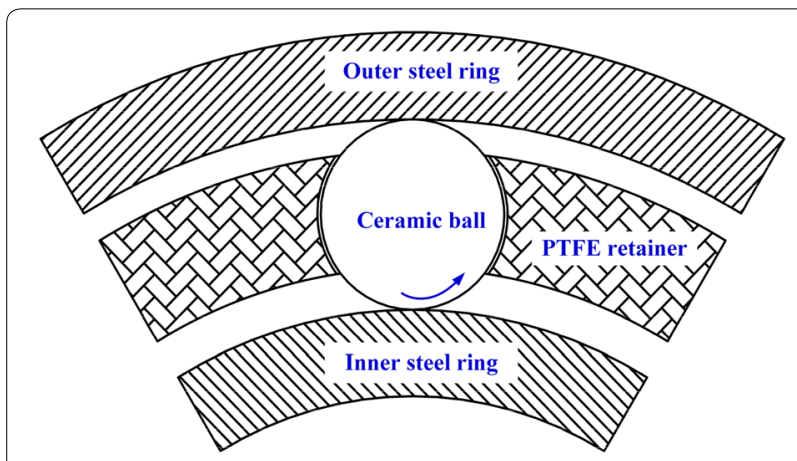

Figure 4 Structural features of a hybrid ceramic ball bearing

high reliability for rocket turbopumps, bearing materials have achieved significant improvements [29]. Until now, the most outstanding structural improvement to REBs of rocket turbopumps is the development of $\mathrm{Si}_{3} \mathrm{~N}_{4}$ ceramic bearings, which have been widely used in heavy rocket turbopumps. The mechanical performance of $\mathrm{Si}_{3} \mathrm{~N}_{4}$ ceramic is far superior to that of common bearing steels. As presented in Table 1 , the hardness of $\mathrm{Si}_{3} \mathrm{~N}_{4}$ is approximately 100 times that of GCr15 and M50, and its coefficient of thermal expansion is much smaller, which can generate less deformation under a low-temperature operational environment. The density of $\mathrm{Si}_{3} \mathrm{~N}_{4}$ ceramic is approximately half that of common bearing steels and is beneficial for the design of low-weight turbopump systems.

However, the machining property of $\mathrm{Si}_{3} \mathrm{~N}_{4}$ ceramic is poor due to its brittleness. The $\mathrm{Si}_{3} \mathrm{~N}_{4}$ rollers are usually fabricated by a sintering process with the necessary subsequent refining processes [30]. Their most common failure case falls into the breakdown mode. In the NASA space shuttle main engine, the improved high-pressure oxidizer turbopump adopted a hybrid type of ceramic bearings, which consisted of $\mathrm{Si}_{3} \mathrm{~N}_{4}$ ceramic balls, a PTFE retainer and steel rings, as shown in Figure 4. Such bearing is an optimized design scheme that reduces the serious wear of all-steel REBs. During operations, the PTFE retainer, with a good self-lubrication performance, can form a thin PTFE transfer film between the rollers and rings [31, 32], which can further improve the tribological performance of the REB.

It should be noted that the PTFE retainer can easily be broken owing to its low strength. Additionally, the ceramic balls will cause a very large contacting stress with the rings owing to their high elastic modulus and low Poisson ratio, which is a common problem of ceramic materials.

\section{Bearing Candidates for the Next Generation of Reusable Liquid Rocket Turbopumps}

Although outstanding structural improvements have been achieved in REBs, their limitations are becoming increasingly prominent for the development of the future reusable and heavy rockets. Further expansion of REBs' potential capacity is quite difficult with the current bearing materials. A new type of bearing with long service life and high reliability is urgently needed for the development of the next generation of reusable liquid rocket turbopumps. In fact, the major space powers worldwide, including China, USA, Russia, France, Japan, and South Korea, have already been engaged in the relevant studies. They have attempted to replace the REBs by new types of bearings and have investigated their operational performance in cryogenic turbopump environments. These promising bearing candidates include fluid-film, foil, magnetic, and other novel bearings. They will be introduced and summarized in detail in the following sections.

\subsection{Fluid-Film Bearings}

Widely used in heavy rotating machinery, fluid-film bearings can form a pressurized fluid film through a hydrodynamic or hydrostatic effect [33-35]. The journal will be separated from the bearing bore by the fluid film, and the mechanical contacting will be transferred into a solid-liquid mode. Generally, the friction coefficients of solid-solid, solid-liquid and solid-gas pairs are 0.1-1, $10^{-4}-10^{-3}$, and smaller than $10^{-4}$, respectively [36]. Thanks to the small friction coefficient and the concomitant less wear, fluid-film bearings have a longer service life than REBs.

As early as at the beginning of the 1980s, NASA already attempted to introduce fluid-film bearings into the rocket turbopump. In 1983, Hannum et al. [37] proposed a bearing combining rolling and hydrostatic fluid-film bearings, as shown in Figure 5. The combination bearing contains two angular contact ball bearings installed in a rotating journal. The rotating journal and the shell form a hydrostatic fluid-film bearing. High-pressure fluid enters the bearing clearance through restrictors and finally generates a hydrostatic fluid film. The researchers adopted the combination bearing into the MK48 turbopump rotor 


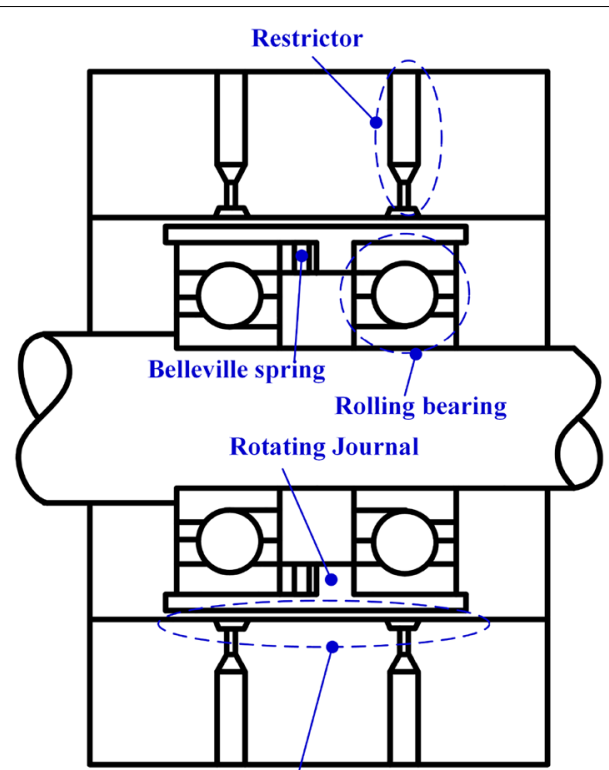

Hydrostatic fluid-film bearing

Figure 5 Combination bearing with rolling and hydrostatic fluid-film bearings [37]

system and conducted 337 start-up experiments. The working medium for the hydrostatic fluid-film bearing was $\mathrm{LH}_{2}$ and the maximum rotational speed was $70000 \mathrm{r} /$ min. After the completion of all the experiments, the wear degree of the two REBs was very smooth. The introduction of the hydrostatic fluid-film bearing relieved the working conditions of the REBs significantly. Later, Polyakov et al. [21] enriched the structures of the combination bearing and several similar bearings were proposed based on the same design principle.

After that, numerous researchers have tried to replace completely the REBs in rocket turbopumps with fluidfilm bearings, including hydrostatic, hydrodynamic and hybrid fluid-film bearings. Regarding the hydrostatic fluid-film bearing scheme, the most famous program was TPX, a $\mathrm{LH}_{2}$ turbopump demonstration program launched by Snecma and Volvo Aero Corporation in 2005 [38-40]. This program reached its conclusion in 2010 with a successful test campaign [41]. The hybrid fluid-film bearing can overcome the external load through simultaneous hydrostatic and hydrodynamic fluid-film forces. The basic structural features of hybrid fluid-film bearings are similar to those of common hydrostatic fluidfilm bearings, and the only difference lies in the bearing clearance. To generate a hydrodynamic fluid field under high speed, the bearing clearance must be small enough. In 1999, Ohta et al. [42] tested a hybrid fluid-film bearing with ten hydrostatic cavities for the Japanese LE-5 rocket turbopumps. Figure 6 illustrates the structural features of

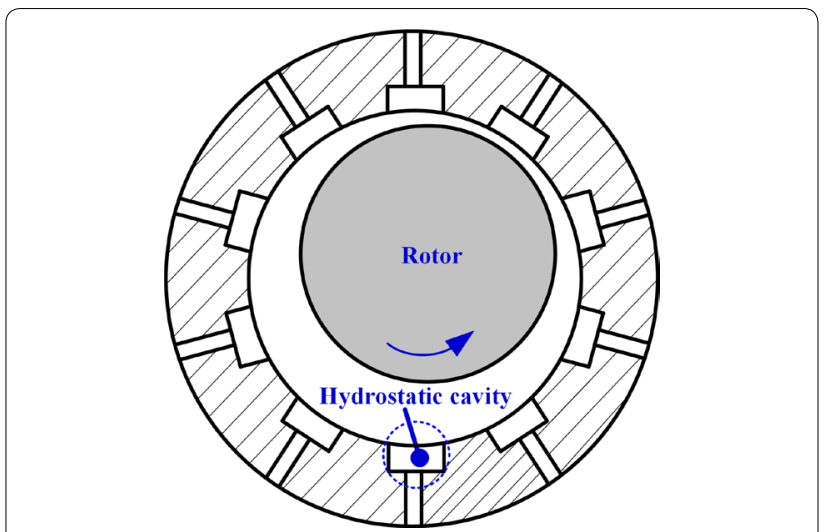

Figure 6 Hybrid fluid-film bearing with ten hydrostatic cavities [38]

the tested bearing. The inner dimeter is $52.1 \mathrm{~mm}$ and the average bearing clearance is $50 \mu \mathrm{m}$. The working medium for experiments is $\mathrm{LH}_{2}$. At the start-up stage, high-pressure $\mathrm{LH}_{2}$ was pumped into the bearing clearance and the rotor was suspended by the hydrostatic effect directly. When the rotational speed reached $50000 \mathrm{r} / \mathrm{min}$, the high-pressure $\mathrm{LH}_{2}$ was removed and the rotor system could be lifted only by the generated hydrodynamic fluid field. Around 2010, Prof. Childs, from Texas A\&M University, proposed the hybrid fluid-film bearing scheme for the next generation of reusable rocket turbopumps in the USA. They used water and air to simulate the low-viscosity medium of the turbopumps and numerous experiments on the start-up characteristics were conducted $[43,44]$. The maximum speed in the experiments was $3000 \mathrm{r} / \mathrm{min}$. They considered that a safe and reliable startup process was the key for the practical service of hybrid fluid-film bearings.

Our team is the pioneer in conducting application feasibility studies of fluid-film bearings for rocket turbopumps in China. Fluid-film bearings with four hydrostatic cavities, as shown in Figure 7, are used for experimental verifications of rotor lifting. The turbopump rotor is supported by two experimental bearings and a displacement sensor installed in the middle is used to monitor the change in vertical height. The inner dimeter and width of the bearing are $30 \mathrm{~mm}$ and $16 \mathrm{~mm}$, respectively. Each cavity has a depth of $27 \mu \mathrm{m}$, a length of $15.7 \mathrm{~mm}$, and a width of $10.5 \mathrm{~mm}$. The working medium for the experiments is liquid nitrogen. The density and viscosity of liquid nitrogen are $813.7 \mathrm{~kg} / \mathrm{m}^{3}$ and $82.3 \times 10^{-6} \mathrm{~Pa} \cdot \mathrm{s}$, respectively. During the experiments, high-pressure liquid nitrogen is pumped into the cavities through orifice throttles with a diameter of $0.5 \mathrm{~mm}$. As shown in Figure 8, the lift height of the rotor increases with the fluid pressure. When the pressure reaches approximately $6 \mathrm{MPa}$, the lift height increases 

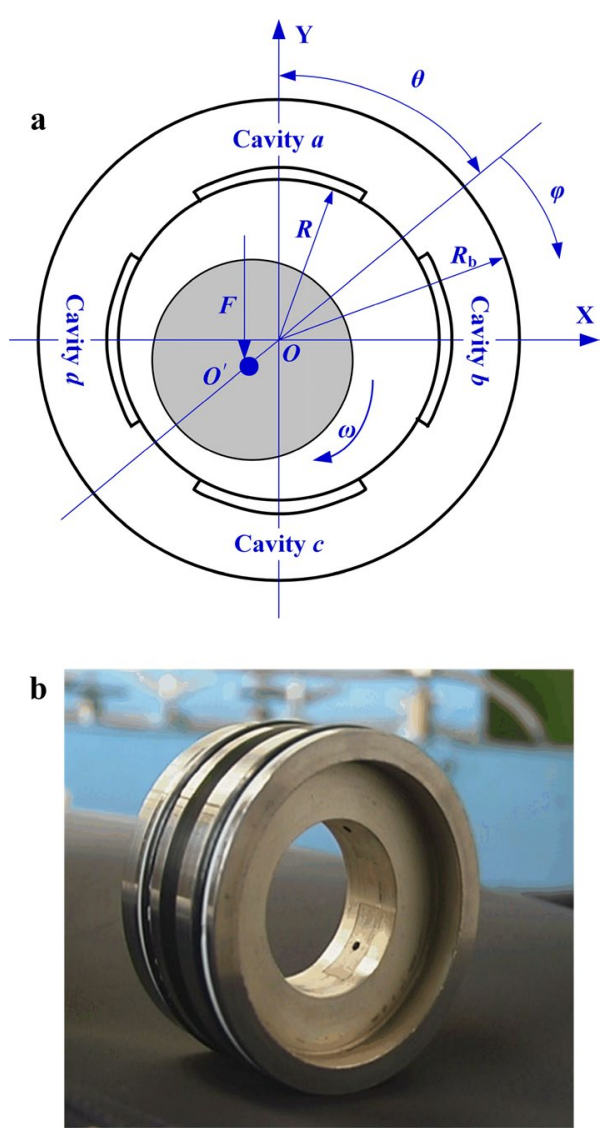

Figure 7 a Structural diagram of hybrid fluid-film bearing with four hydrostatic cavities, $\mathbf{b}$ photograph of the real bearing

to $20-22 \mu \mathrm{m}$ and is stable after that. We use a program based on the Reynolds theory to calculate the dynamic characteristics of this bearing. Under the rotational speed of $30000 \mathrm{r} / \mathrm{min}$, the average values of the main stiffness and main damping coefficients are about $100 \times 10^{6} \mathrm{~N} / \mathrm{m}$ and $200 \times 10^{6} \mathrm{~N} \cdot \mathrm{s} / \mathrm{m}$, respectively. The high stiffness and damping are beneficial for the high-speed stability of the rotor system.

However, the source of the high-pressure fluid is a significant obstacle for practical applications of hydrostatic and hybrid fluid-film bearings. Especially at the start-up stage, the mechanical wear will be more severe than that of REBs if the rotor cannot be lifted successfully. However, once the system can pass the start-up stage safely, the hydrodynamic effect at high speed can be well qualified for harsh working conditions. Our team previously proposed a scheme involving the addition of a high-pressure pump or an accumulator to the turbopump system [45]. As shown in Figure 9, the turbopump rotor system is suspended by high-pressure fluid from the accumulator at the start-up stage. When
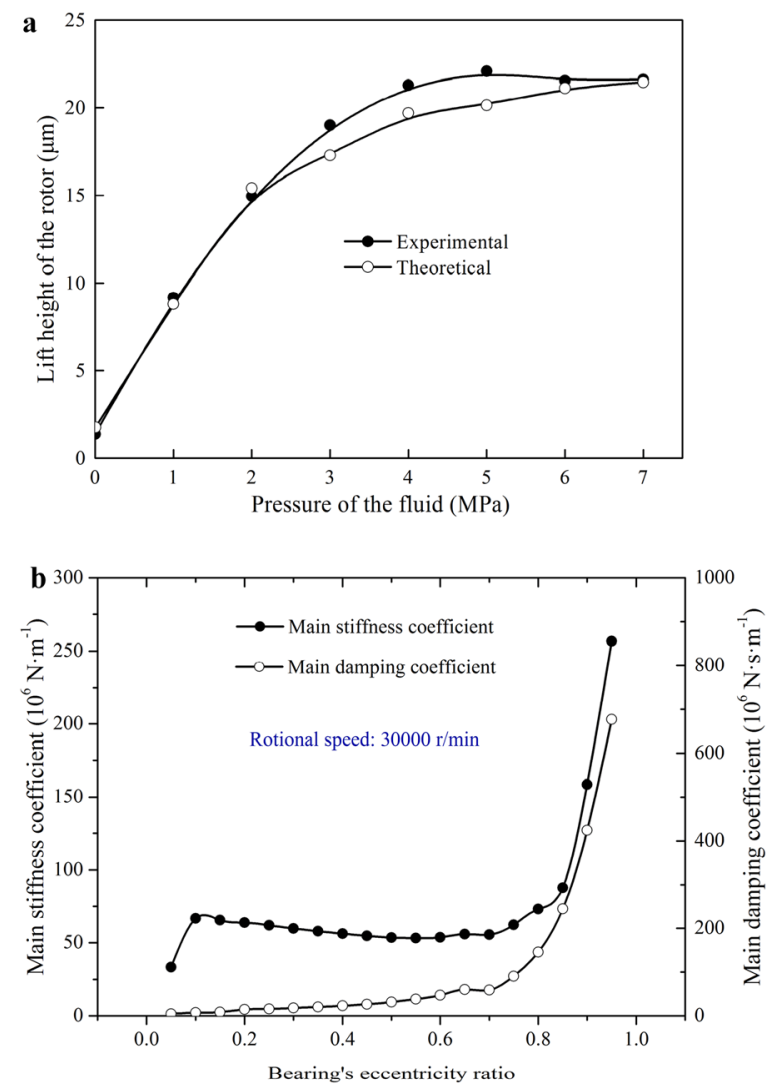

Figure 8 a Lift height of the rotor support by a fluid-film bearing, $\mathbf{b}$ dynamic characteristics of the fluid-film bearing

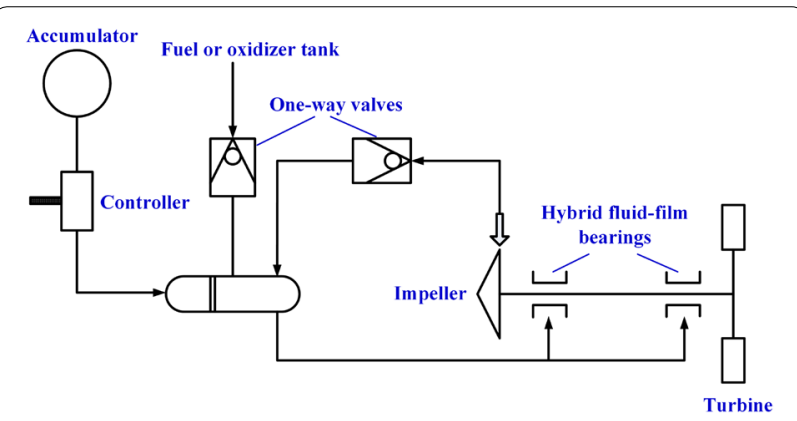

Figure 9 Application scheme of hybrid fluid-film bearings by adding an accumulator

the speed is high enough, the hydrodynamic fluid field will be the dominant part for overcoming external loads. This application scheme will definitely increase the weight of the turbopump and system risk owing to the additional components. In summary, solving the start-up problem perfectly is the key for the practical service of fluid-film bearings. 


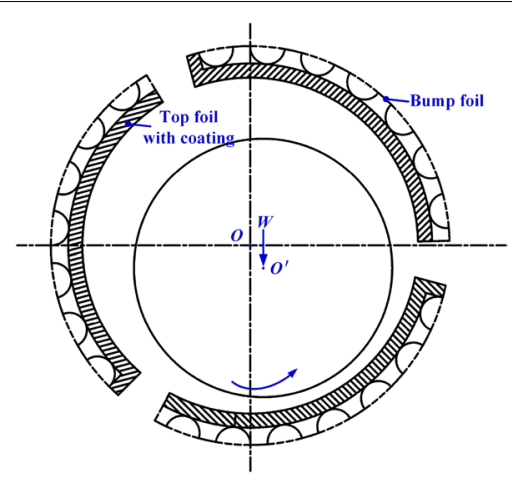

Figure 10 Structural features of a compliant fluid foil bearing

\subsection{Foil Bearings}

Foil bearings have been successfully used in high-speed turbomachines, and they present a remarkable reliability. For aircraft turbo-compressors, the mean-time-betweenfailure is typically over $60000 \mathrm{~h}[46,47]$. Figure 10 illustrates the structural features of a compliant foil bearing, which consists of top foils and bump foils.

The operational mechanism of foil bearings is similar to that of fluid-film bearings. At the start-up stage, the rotor journal and the bearing bore are contacting each other directly. Once the rotational speed crosses the critical point, the rotor will be suspended by the generated pressure fluid film. As the stiffness of the foils is much smaller than that of the fluid film, the foil bearings can adapt to various working conditions through foil deformations. Specially, the range between the second and third critical speeds of the foil bearing-rotor system is very large, which means that the foil bearings can suspend the rotor at a very high speed stably. Owing to these advantages, foil bearings are identified as a potential alternative for REBs. If properly designed and operated, foil bearings would incur very slight wear and have a long service life [48].

In the 1990s, NASA conducted various tests of foil bearings in $\mathrm{LH}_{2}$ and $\mathrm{LO}_{2}$ environments $[49,50]$. Stoltzfus et al. [51] tested the material compatibility of three candidate polymer coatings for $\mathrm{LH}_{2}$ lubricated foil bearings at the NASA White Sands Test Center. There were no ignition hazards during the frictional heating tests, which means that these polymer coatings can be used in the establishment of foil bearing turbopumps. After that, $\mathrm{LH}_{2}$ foil bearing turbopump and $\mathrm{LO}_{2}$ turbopump demonstrations were conducted subsequently [52]. The experimental scheme is displayed in Figure 11. The experimental highlights of the NASA foil bearing turbopump demonstrations are listed in Table 2. In 1992, the $\mathrm{LH}_{2}$ foil bearing turbopump was successfully tested in NASA Stennis Space Center. The maximum rotational speed

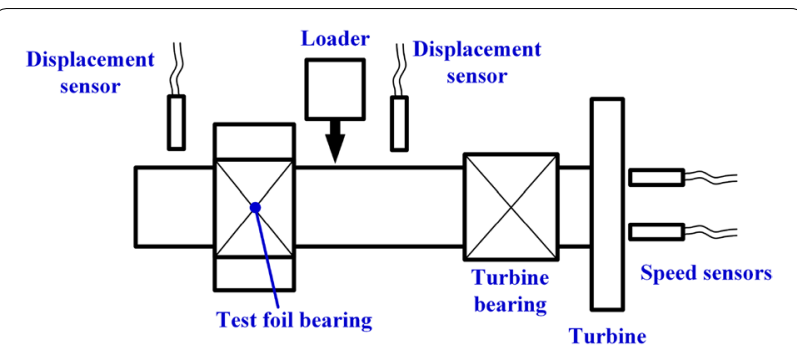

Figure 11 Experimental scheme of NASA foil bearing turbopump demonstrations [52]

was $91000 \mathrm{r} / \mathrm{min}$. After over 100 times of a frequent start/ stop, the foil bearings and rotating assembly were still in excellent condition. In 1993, a $\mathrm{LO}_{2}$ turbopump demonstration was successfully conducted in NASA Marshall Space Flight Center. The maximum rotational speed was $25000 \mathrm{r} / \mathrm{min}$ and the total start/stop times were over 100 .

However, foil bearings have not yet been adopted in any rocket turbopump in service. In fact, the working principle of foil bearings is almost identical to that of fluidfilm bearings, and thus, the start-up problem still exists. Although bearing coatings were adopted, some debris particles with a size of approximately $0.51 \mathrm{~mm}$ were still found in NASA foil bearing turbopump demonstrations and the bearing surface was scratched by them to some extent. This is a potential hazard for a safe service, which cannot be ignored.

\subsection{Magnetic Bearings}

To obtain fully mechanical-friction free bearings from start-up to stop, some researchers attempted to introduce magnetic bearings into rocket turbopumps. Since 1986, the SEP Company in France had conducted some conceptual and technological studies about the feasibility of active magnetic bearings (AMBs) in rocket turbopumps [53]. Theoretically, the rotor can be suspended in the space by the magnetic field of AMBs, which can ensure no mechanical friction and wear $[54,55]$. Their high reliability, long life, and high rotational speed are attractive for rocket turbopumps. However, AMBs also have some drawbacks, as they need a strong electricity power supply, a complicated control system, and safe compatibility with a cryogenic fuel. Specially, the safety operation under a cryogenic environment is still in doubt although some design improvements have been proposed [56].

The superconducting magnetic bearing (SMB) has also been considered by researchers. The finding of the $\mathrm{Y}-\mathrm{Ba}-\mathrm{Cu}-\mathrm{O}$ superconductor with a transformation temperature of $92 \mathrm{~K}$ makes the application prospects of SMBs fascinating [57]. The pinning effect of a magnetic flux in such superconductors can make them be 
Table 2 Experimental highlights of NASA foil bearing turbopump demonstrations

\begin{tabular}{|c|c|c|c|c|}
\hline Item & Experimental site & Rotational speed ( $r / \mathrm{min})$ & Total run time & $\begin{array}{l}\text { Total } \\
\text { start/stop } \\
\text { times }\end{array}$ \\
\hline $\begin{array}{l}\mathrm{LH}_{2} \text { foil bearing tur- } \\
\text { bopump demonstra- } \\
\text { tion }\end{array}$ & NASA Stennis Space Center & 14000-91000 & Approximately $60 \mathrm{~min}$ & 100 \\
\hline $\begin{array}{l}\mathrm{LO}_{2} \text { foil bearing tur- } \\
\text { bopump demonstra- } \\
\text { tion }\end{array}$ & NASA Marshall Space Flight Center & $2000-25000$ & Approximately 90 min & 100 \\
\hline
\end{tabular}

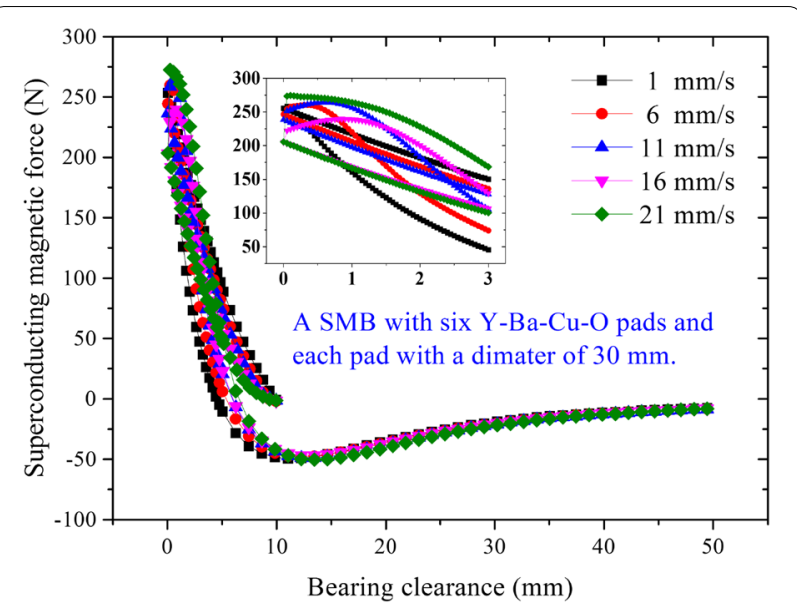

Figure 12 Superconducting magnetic force of an axial-type SMB

suspended in a nonhomogeneous external magnetic field without active control, which is called passive self-stability. Moreover, the natural cryogenic environment in rocket turbopumps can save the cooling cost of SMBs. However, a fatal drawback affects the application process, namely, the extremely low stiffness and damping coefficients. As shown in Figure 12, we tested the magnetic force of an axial-type SMB to analyze their dynamic characteristics. The matching rotor assembly contains a Nd-Fe-B permanent magnet with concentrating surface magnetic flux density of up to $0.5 \mathrm{~T}$. The $\mathrm{SMB}$ is constituted by six $\mathrm{Y}-\mathrm{Ba}-\mathrm{Cu}-\mathrm{O}$ superconducting pads and each pad has a diameter of $30 \mathrm{~mm}$. To simplify the analysis, the SMB rotor system is viewed as a model of mass-spring-damper. The total magnetic force consists of two parts: damping force $F_{d s}$ and oscillatory force $F_{k s}$. The formulas of $F_{d s}$ and $F_{k s}$ are as follows:

$$
\left\{\begin{array}{l}
F_{d s}=-c_{s} \dot{z}_{s} \\
F_{k s}=-k_{s} z_{s}
\end{array}\right.
$$

where $z_{s}$ is bearing clearance, $\dot{z}_{s}$ is the relative speed between the bearing and the rotor, $k_{s}$ is the stiffness coefficient of the SMB system, and $c_{s}$ is the damping coefficient.

The approximate stiffness and damping coefficient at certain bearing clearance can be calculated by Eq. (1) through simple numerical calculations. The average values with bearing clearance of less than $3 \mathrm{~mm}$ are approximately $33094 \mathrm{~N} / \mathrm{m}$ and $604.5 \mathrm{~N} \cdot \mathrm{s} / \mathrm{m}$, respectively. Compared with the fluid-film bearings in Section 3.1, the dynamic characteristics of SMB are too small to maintain a stable operation.

As SMBs can suspend the rotor system at a static state, we introduced the superconducting magnetic field into the hybrid fluid-film bearings to replace the hydrostatic fluid field. The insufficient dynamic characteristics at high-speed will be compensated by the hydrodynamic fluid field. The corresponding studies won the 2018 HIWIN Doctoral Dissertation Award.

\subsection{Superconducting Compound Bearings Proposed by Our Team}

As summarized above, the major space powers have conducted substantial explorations on long-life and high-reliability alternative bearings for reusable rocket turbopumps. These bearing candidates cannot fully meet the requirements of mechanical-friction free and high stability simultaneously from the start-up to the stop stage. However, they all have remarkable advantages under certain working conditions. Therefore, our team proposed a novel superconducting compound bearing to combine the advantages of SMBs and fluid-film bearings [58-61].

Figure 13 displays the structural diagram of axial-type and radial-type superconducting compound bearings. They are constituted by several superconducting tilting pads, which further can enhance the high-speed stability [62]. Each pad consists of copper sheathing and circular $\mathrm{Y}-\mathrm{Ba}-\mathrm{Cu}-\mathrm{O}$ superconductors. The good machining property of copper can make it possible to adapt the bearing surface roughness to the requirement of small bearing clearance. During operation, the whole bearing is totally submerged in cryogenic media. The cryogenic fuel or oxidizer is used simultaneously as cooling medium of the 

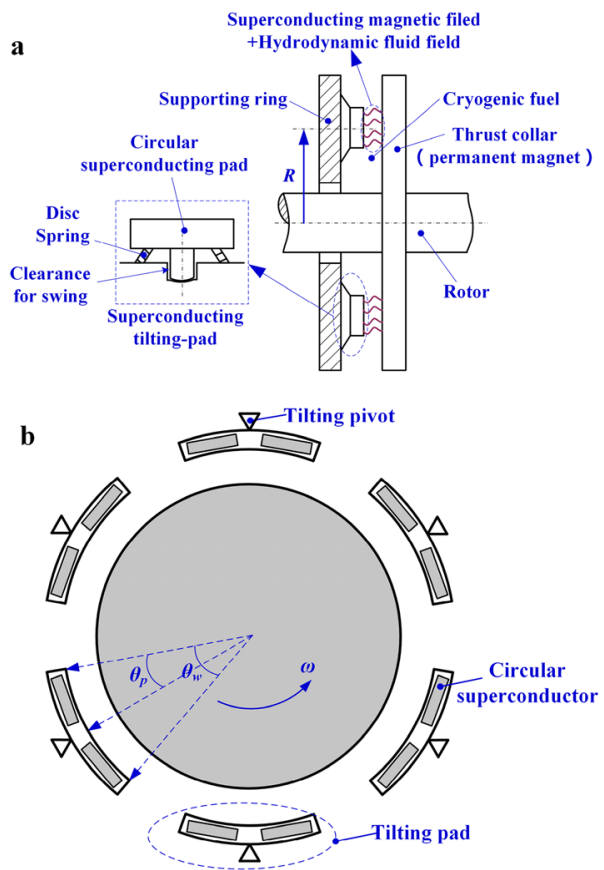

Figure 13 a Structures of axial-type superconducting compound bearings, $\mathbf{b}$ structures of radial-type superconducting compound bearings

SMB and lubricating medium of the fluid-film bearing. The pad can produce a micro swing to form a convergent clearance, which is a necessary condition to generate a hydrodynamic field.

The superconducting compound bearings can ensure simultaneously low friction during the start/stop stages and high stability during the stable working stage. The operational principle is illustrated in Figure 14. At the start-up, stop and low-speed stages, the rotational speed cannot support the generation of the hydrodynamic fluid field, and the rotor will be suspended by the superconducting magnetic field. With the increase in speed, the hydrodynamic effect starts to be present and cooperates with the superconducting magnetic field to overcome the external load. Finally, the hydrodynamic fluid field will play the dominant role at the stable high-speed working stage. Such relay type of carrying mode perfectly solves the drawbacks of the severe mechanical friction at the start-up in common fluid-film bearings and the low dynamic coefficients in SMBs.

Figure 15 shows the vibration amplitude of the superconducting compound bearing under sine excitation. The rotational speed is $30000 \mathrm{r} / \mathrm{min}$. The maximum vibration amplitude of the superconducting compound bearing is $33.3 \mu \mathrm{m}$, whereas, the maximum amplitude without the compound of fluid field is $3.01 \mathrm{~mm}$. The stiffness coefficient of the superconducting compound bearing is

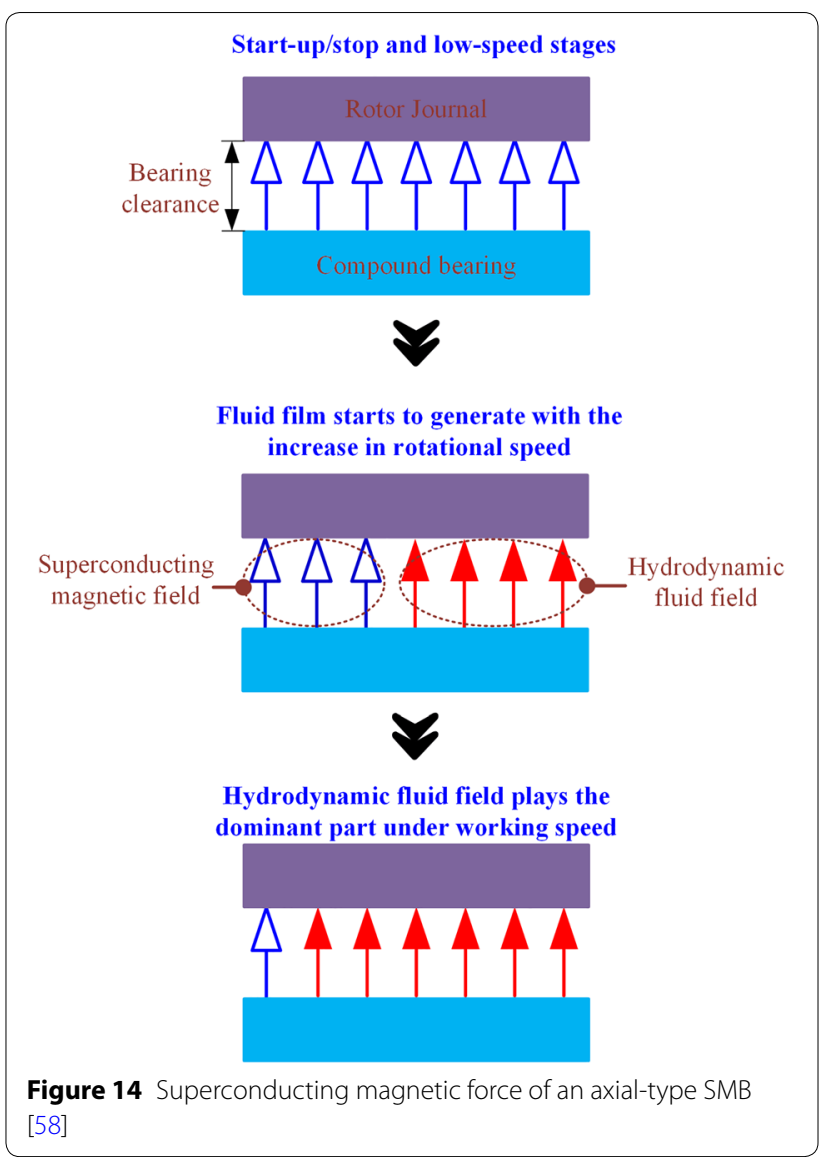

approximately 100 times that of the SMB. Because of the improvement in dynamic characteristics, the ability of the superconducting compound bearing to stand high and impact loads is substantially improved.

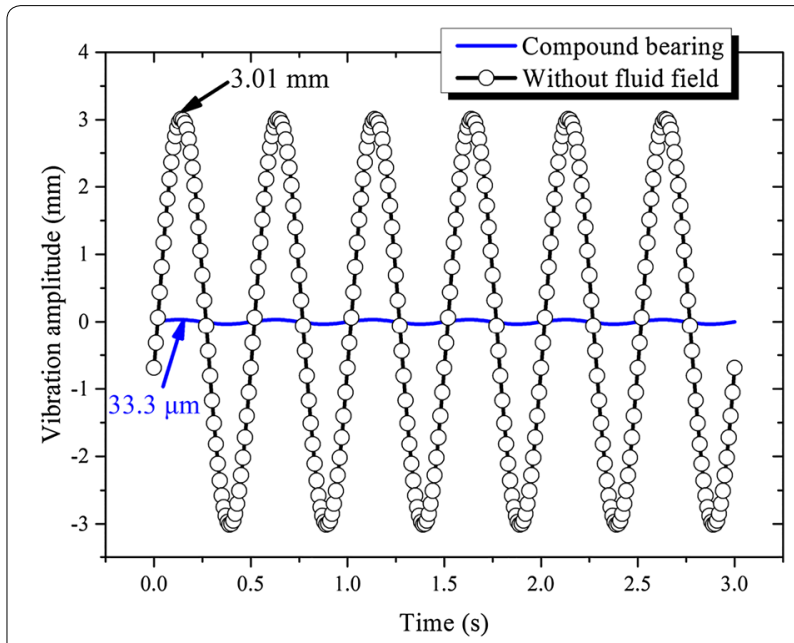

Figure 15 Vibration amplitude of the superconducting compound bearing [59] 
We established a high-speed experimental device to verify the feasibility of the compound mechanism, as shown in Figure 16. An axial-type superconducting compound bearing with six superconducting tilting pads is used for the experiments. The matching thrust collar is prepared with an Nd-Fe-B permanent magnet. The bearing clearance can be adjusted by a high-precision servo system and the bearing force is measured directly by the pressure sensor under the bearing pedestal. Liquid nitrogen is used as a cooling and lubricating medium. The maximum experimental speed is $10000 \mathrm{r} / \mathrm{min}$ and the minimum bearing clearance is $0.1 \mathrm{~mm}$. The total superconducting magnetic force of six pads at $0.1 \mathrm{~mm}$ is approximately $382 \mathrm{~N}$. During the experiments, no
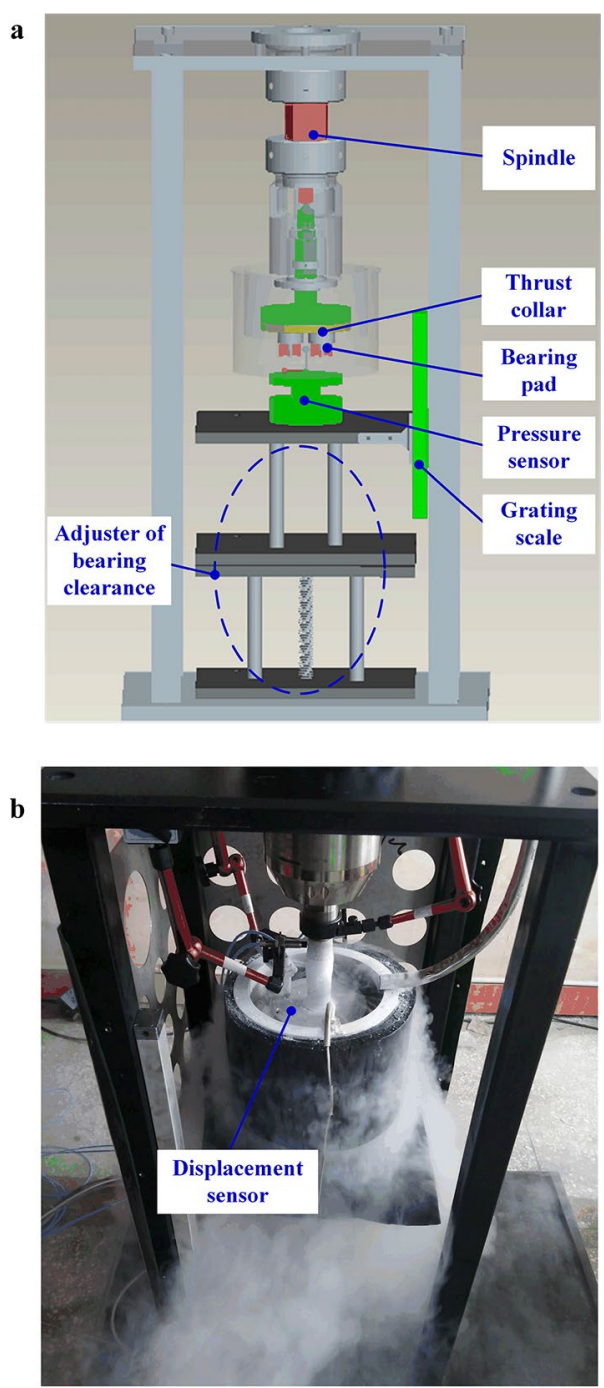

Figure 16 a Structural diagram of a high-speed experimental device for superconducting compound bearings. b Photograph of the experiment device obvious evidence can prove the generation of a hydrodynamic fluid-film force when the bearing clearance is larger than $0.1 \mathrm{~mm}$. With the decrease in bearing clearance, a sudden increase in bearing force (approximately $19.2 \mathrm{~N}$ ) occurs around $0.1 \mathrm{~mm}$, which means the generation of a hydrodynamic fluid film force [16]. The bearing capacity can be significantly improved by the increase in rotational speed and the decrease in bearing clearance. These tests should be conducted in an aerospace department setting instead of laboratory environment.

Generally, the compound feasibility of the superconducting magnetic field and hydrodynamic fluid field has been verified by experiments. Such compound can achieve superior dynamic characteristics and high stability under high speed, which correspond to a real long-life and high-reliability bearing candidate. The working speed for the current heavy liquid rocket engine is approximately $30000 \mathrm{r} / \mathrm{min}$ because of the life limitation of REBs. If such compound bearing can be used, the rotational speed value can be improved by several times, which is a huge booster for improving launch capacity. More importantly, the principle compound approach can be beneficial for solving the application obstacles of the other abovementioned bearing candidates.

\section{Conclusions and Outlooks}

For the development of the next generation of reusable liquid rocket turbopumps, this review summarizes the bearing candidates for replacing REBs in existing rocket turbopumps, including fluid-film, foil, and magnetic bearings, along with the novel superconducting magnetic bearings. The merits and demerits of these new types of bearings are summarized in Table 3.

The following conclusions and outlooks can be obtained:

1) A long-life and highly reliable bearing is the key technology for developing the next generation of reusable liquid rocket turbopumps. Although the hybrid ceramic ball bearing has been proposed to improve the performance of REBs, further expansion of REBs' potential is becoming increasingly difficult with the current bearing materials. The inherent reason lies in the conflict between the improvement of turbopump speed and the life limitation of REBs.

2) Substantial explorations about the application feasibility of fluid-film bearings in rocket turbopumps have been conducted. Their superior dynamic characteristics make them a very promising bearing candidate. As the wear will be more severe than that in REBs if the rotor cannot be lifted successfully, solving the start-up problem perfectly is the key for the practical service of fluid-film bearings. 
Table 3 Summary of merits and demerits of the new types of bearings

\begin{tabular}{|c|c|c|}
\hline New-type bearings & Merits & Demerits \\
\hline Hydrostatic fluid-film bearings & Free of mechanical friction at the working stage & Must be equipped with a high-pressure pump \\
\hline Hybrid fluid-film bearing & $\begin{array}{l}\text { Free of mechanical friction and superior dynamic } \\
\text { performance at the working stage }\end{array}$ & $\begin{array}{l}\text { Severe mechanical friction and wear at the start-up } \\
\text { stage }\end{array}$ \\
\hline Foil bearing & $\begin{array}{l}\text { Except for the merits of the hybrid fluid-film bearing, } \\
\text { this bearing can adapt to various working conditions } \\
\text { through foil deformations }\end{array}$ & Mechanical friction and wear at the start-up stage \\
\hline AMB & $\begin{array}{l}\text { Free of mechanical friction from the start-up to stop } \\
\text { stages }\end{array}$ & $\begin{array}{l}\text { Safe operation under a cryogenic environment is still } \\
\text { in doubt }\end{array}$ \\
\hline $\mathrm{SMB}$ & Self-stable suspension from the start-up to stop stages & Poor dynamic characteristics \\
\hline Superconducting compound bearing & The merits of the SMB and hybrid fluid-film bearing & $\begin{array}{l}\text { Without demerits theoretically, but need more evalu- } \\
\text { ations }\end{array}$ \\
\hline
\end{tabular}

3) The operational principle of foil bearings is almost identical to that of the hydrodynamic fluid-film bearings. The foil deformation can make it possible for foil bearings to adapt to various working conditions. NASA has conducted $\mathrm{LH}_{2}$ and $\mathrm{LO}_{2}$ foil bearing turbopump demonstrations successfully. However, some debris particles with a size of $0.51 \mathrm{~mm}$ were found in the experiments, and this is a potential hazard for rocket turbopumps.

4) For AMBs, their safe operation under a cryogenic environment is still in doubt. The SMBs can suspend the rotor system at a static state but have poor dynamic characteristics at high speed. Therefore, we introduce the superconducting magnetic field into the hybrid fluid-film bearings to replace the hydrostatic fluid field. The insufficient dynamic characteristics at high-speed will be compensated by the hydrodynamic fluid field.

5) The superconducting compound bearing proposed by our team combines the advantages of fluid-film bearings and SMBs, and it can simultaneously ensure low friction during the start/stop stages and high stiffness during the stable working stage. The compound feasibility has been verified at a high-speed experimental device and further improvements in bearing capacity should be conducted by aerospace departments.

6) Based on the state of the art, research and application schemes of the feasible bearing candidates for developing the next generation of reusable liquid rocket turbopumps can adopt a similar compound approach.

\section{Acknowledgements}

The authors sincerely thanks to Dr. Zhi Li from Tokyo University of Marine Science and Technology, Japan for his critical discussion and proofreading during manuscript preparation.

\section{Authors' Contributions}

JX was in charge of the research projects and the whole trial; $\mathrm{CL}$ and XM were responsible for the corresponding research of fluid-film bearings; CZ was responsible for the corresponding research of superconducting magnetic bearings and $X Y$ was responsible for the research idea of the superconducting compound bearing. All authors read and approved the final manuscript.

\section{Authors' Information}

Jimin Xu, born in 1989, is currently a Lecturer at Institute of Tribology, School of Mechanical Engineering, Hefei University of Technology, China. He received his Ph.D. degree from Xi'an Jiaotong University, China, in 2017. His research interests include Bearing Technology and Superconducting maglev.

Changhuan Li, born in 1980, is currently a senior engineer at Xi'an Aerospace Propulsion Institute, China Aerospace Science and Technology Corporation, China. Her research interests include liquid rocket turbopump system and combustion engineering.

Xusheng Miao, born in 1971, is currently a senior engineer at Xi'an Aerospace Propulsion Institute, China Aerospace Science and Technology Corporation, China and a Ph.D. candidate at Science Technology on Combustion, Internal Flow and Thermal-structure Laboratory, Northwestern Polytechnical University, China. His research interests include liquid rocket turbopump system and combustion engineering.

Cuiping Zhang, born in 1968, is currently a senior engineer at Superconducting Materials Research Center Laboratory, Northwest Institute for Non-ferrous Metal Research, China. She received her Ph.D. degree from Northwestern Polytechnical University, China. Her main research interest is superconducting technology.

Xiaoyang Yuan, born in 1963, is currently a professor at Xi'an Jiaotong University, China. He received his PhD degree from Xi'an Jiaotong University, China, in 1997. His research interests include lubricating technology and modern mechanical design.

\section{Funding}

Supported by National Natural Science Foundation of China (Grant No. 51805131), Postdoctoral Research Foundation of China (Grant No. 2018M640580) and Fundamental Research Funds for the Central Universities (CN) Fundamental Research Funds for the Central Universities of China (Grant No. JZ2018HGBZ0155)

\section{Competing Interests}

The authors declare no competing financial interests.

\section{Author Details}

${ }^{1}$ Institute of Tribology, School of Mechanical Engineering, Hefei University of Technology, Hefei 230009, China. ${ }^{2}$ Aerospace Propulsion Institute, China Aerospace Science and Technology Corporation, Xi'an 710100, China.

${ }^{3}$ Science Technology on Combustion, Internal Flow and Thermal-structure Laboratory, Northwestern Polytechnical University, Xi'an 710012, China. 
${ }^{4}$ Superconducting Materials Research Center Laboratory, Northwest Institute for Non-ferrous Metal Research, Xi'an 710016, China. ${ }^{5}$ Key Laboratory of Education Ministry for Modern Design and Rotor-Bearing System, Xi'an Jiaotong University, Xi'an 710049, China.

Received: 31 July 2019 Revised: 9 January 2020 Accepted: 5 March 2020 Published online: 17 March 2020

\section{References}

[1] A Degtyarev, A Kushnaryov, V Shulga, et al. Yuzhnoye's new liquid rocket engines as enablers for space exploration. Acta Astronautica, 2016, 127 : 693-698.

[2] J Foust. China promises the moon. IEEE Spectrum, 2018, 55 (1): 26-29.

[3] KO Kim, T Roh, J W Lee, et al. Derating design for optimizing reliability and cost with an application to liquid rocket engines. Reliability Engineering \& System Safety, 2016, 146: 13-20.

[4] Y Boure, PVinet, S Magniant, et al. LOX/methane reusable rocket propulsion at reach with large scale demonstrators tested. Acta Astronautica, 2018, 152: 542-556.

[5] SW Feng, Z H Ma, YTWu, et al. Survey and review on key technologies of reusable launch vehicle abroad. Missiles and Space Vehicles, 2014, 335: 84-88. (in Chinese)

[6] SR Dalar, E B Fowlkes, B Hoadley. Risk analysis of the space shuttle: prechallenger prediction of failure. Journal of the American Statistical Association, 1989, 84: 945-957.

[7] D Zimpfer, P Hattis, J Ruppert, et al. Space shuttle GN\&C development history and evolution. AIAA Space 2011 Conference \& Exposition, California, USA, September 27-29, 2011: AIAA 2011-7244.

[8] A D Lance. First stage recovery. Engineering, 2016, 2(2): 152-153.

[9] A D Lance. Falcon heavy. Engineering, 2018, 4(3): 300-300.

[10] Q Liu. Reliability growth test evaluation methods for liquid rocket engine. Changsha: National University of Defense, 2003.

[11] B H Ertas, E Al-Khateeb, J M Vance. Rotordynamic bearing dampers for cryogenic rocket engine turbopumps. Journal of Propulsion and Power, 2003, 19(4): 674-682.

[12] S M Frolov, V S Aksenov, V S Ivanov, et al. Rocket engine with continuous detonation combustion of the natural gas-oxygen propellant system. Physical Chemistry, 2018, 478(2): 31-34.

[13] B Li, X P Zhang, Y S Gao. Consideration on development of reusable liquid rocket engine in China. Journal of Rocket Propulsion, 2017, 43(1): 1-7. (in Chinese)

[14] M Nosaka, T Kato. Cryogenic tribology in high-speed bearings and shaft seals of rocket turbopumps. In: J Gegner. Tribology- Fundamentals and Advancements, London: IntechOpen, 2013: 109-153.

[15] W L Murray, M W Steiner, J A Neal, et al. Design and analysis of a high speed, high pressure peroxide/RP-1 turbopump. 50th AIAA/ASME/SAE/ ASEE Joint Propulsion Conference, Cleveland, USA, 2014: AIAA 2014-3499.

[16] J M Xu. Applied fundamental research of superconducting magnetic force and liquid-film force compound bearings. Xi'an: Xi'an Jiaotong University, 2017

[17] DW Childs, D Klooster, H Borchard, et al. Transient lift-off test results for an experimental hybrid bearing in air, simulating a liquid hydrogen turbopump start transient. ASME 2016 Turbomachinery Technical Conference and Exposition, Seoul, South Korea, 2016: GT2016-56310.

[18] G Y Zhang, G Z Chen, W G Zhao, et al. An experimental test on a cryogenic high-speed hydrodynamic non-contact mechanical seal. Tribology Letters, 2017, 65: 80 (11pp).

[19] C Q Bai, QY Xu. Stability analysis of liquid hydrogen turbopump-seal rotor system with internal damping. Aircraft Engineering and Aerospace Technology, 2011, 83(1): 6-13.

[20] L Collongeat, E Edeline, M Frocot. Development status of high DN LH2 bearings in Snecma. 41st AIAA/ASME/SAE/ASME Joint propulsion Conference \& Exhibit, Arizona, USA, 2005: AIAA-2005-3950.

[21] R Polyakov, L Savin, D Shutin. Reliability improvement of rotor supports by combining rolling-element bearings and fluid-film bearings. Applied Mechanics and Materials, 2014, 630: 188-198.

[22] Z Chang, Q Jia, X Yuan, et al. Main failure mode of oil-air lubricated rolling bearings installed in high speed machining. Tribology International, 2017, 112: 68-74.
[23] V Vartha, K M S Arun, S Mathew, et al. Failure analysis of ball-bearing of turbo-pump used in liquid rocket engine. Materials Science Forum, 2015, 830-831: 709-712.

[24] A Neri, E Porcu, N De-Liguori, et al. A new static firing test bench for Zefiro SRM. 40th AIAA/ASME/SAE/ASEE Joint Propulsion Conference and Exhibit, Florida, USA, 2004: AIAA-2004-4214.

[25] K Mao, X S Miao, H Chen, et al. Experimental research on bearing life of turbopump in liquid rocket engine. Journal of Rocket Propulsion, 2016, 42(5): 24-27. (in Chinese)

[26] L Sun, A Li. Rolling-element bearings in China: from ancient times to the 21 th century. Frontiers of Mechanical Engineering, 2016, 11(1): 33-43.

[27] F J Ebert. An overview of performance characteristics, experiences and trends of aerospace engine bearings technologies. Chinese Journal of Aeronautics, 2007, 20: 378-384.

[28] F J Ebert. Fundamentals of design and technology of rolling element bearings. Chinese Journal of Aeronautics, 2010, 23: 123-136.

[29] H K D H Bhadeshia. Steels for bearings. Progress in Materials Science, 2012, 57: 268-435.

[30] J L Li, F Chen, J Y Niu. Low temperature sintering of Si3N4 ceramics by spark plasma sintering technique. Advance in Applied Ceramics, 2011, 110(1): 20-24

[31] M Nosaka, M Kikuchi, M Oike, et al. Tribo-characteristics of cryogenic hybrid ceramic ball bearings for rocket turbopumps: self-lubricating performance. Tribology Transactions, 1997, 40(1): 21-30.

[32] M Nosaka, M Kikuchi, M Oike, et al. Tribo-characteristics of cryogenic hybrid ceramic ball bearings for rocket turbopumps: bearing wear and transfer film. Tribology Transactions, 1999, 42 (1): 106-115.

[33] K P Gertzos, P G Nikolakopoulos, C A Papadopoulos. CFD analysis of journal bearing hydrodynamic lubrication by Bingham lubricant. Tribology International, 2008, 41: 1190-1204.

[34] F Zhang, W Ouyang, H L Hong, et al. Experimental study on pad temperature and film thickness of tilting-pad journal bearings with an elasticpivot pad. Tribology International, 2015, 88: 228-235.

[35] W Ouyang, X B Zhang, Y Jin, et al. Experimental study on the dynamic performance of water-lubricated rubber bearings with local contact. Shock and Vibration, 2018: 6309727 (10pp).

[36] J M Xu, F Zhang, Y Z Jin, et al. Development status and prospects of high- $T_{c}$ superconducting magnetic bearing. Materials China, 2017, 36(5): 321-328. (in Chinese)

[37] N P Hannum, O H Cleveland, C E Nielson. The performance and application of high speed long life hybrid bearings for reusable rocket engine turbomachinery. 19th Joint Propulsion Conference, Washington, USA, June 27-29, 1983: AIAA-83-1389.

[38] E Edeline, P Fayolle, P Fonteyn, et al. Development and testing of a fluid-film bearing LH2 Turbopump demonstrator. 40th AIAA/ASME/SAE/ ASEE Joint Propulsion Conference and Exhibit, USA, Florida, July 11-14, 2004: AIAA 2004-3688.

[39] P Fayolle, J M N Duc, B Pouffary, et al. Progress status of TPX LH2-turbopump demonstration program. 44th AIAA/ASME/SAE/SAE/ASEE Joint Propulsion Conference \& Exhibit, USA, Hartford, July 21-23, 2008: AIAA 2008-4945

[40] P Fayolle, P Fonteyn, F Laithier, et al. Manufacturing and Testing of TPX LH2-turbopump prototype. 46th AIAA/ASME/SAE/ASEE Joint Propulsion Conference \& Exhibit, USA, Nashville, July 25-28, 2010: AIAA 2010-7049.

[41] P Fayolle, P A Lambert, P Gelain, et al. Major achievements reached through TPX LH2-turbopump demonstration program. 47th AIAA/ASME/ SAE/ASEE Joint Propulsion Conference \& Exhibit, USA, San Diego, July 31-03 August, 2011: AIAA 2011-5786.

[42] H Ohta, A Kitamura, H Ogata. LH2 turbopump test with hydrostatic bearing. 35th AIAA/ASME/SAE/ASEE Joint Propulsion Conference and Exhibit, California, USA, June 20-24, 1999: AIAA-99-2195.

[43] H M David. Lift-off performance in flexure pivot pad and hybrid bearing. Texas: Texas A\&M University, 2008.

[44] G K David. Transient lift-off test results for an experimental hybrid bearing in air. Texas: Texas A\&M University, 2009.

[45] X S Miao, B Li, ZY Huang. Application analysis of liquid hybrid bearing for engine turbopump. Journal of Rocket Propulsion, 2004, 30(6): 1-4. (in Chinese)

[46] Y Hou, Z H Zhu, C Z Chen. Comparative test on two kinds of new compliant foil bearing for small cryogenic turbo-expander. Cryogenics, 2004, 44 : 69-72. 
[47] ZY Guo, K Feng, TY Liu, et al. Nonlinear dynamic analysis of rigid rotor supported by gas foil bearings: effects of gas film and foil structure on subsynchronous vibration. Mechanical Systems and Signal Processing, 2018, 107: 549-566.

[48] $\mathrm{H}$ Heshmat $\mathrm{H}$. A feasibility study on the use of foil bearings in cryogenic turbopumps. 27th AIAA/SAE/ASME/ASEE Joint Conference, California, USA, June 24-26, 1991: AIAA-91-2103.

[49] M Saville, A Gu, R Capaldi. Liquid hydrogen turbopump foil bearing. 27th AIAA/SAE/ASME/ASEE Joint Propulsion Conference and Exhibit, California, USA, June 24-26, 1991: AIAA-91-2108.

[50] J S McFarlane, M P Saville, S C Nunez. Testing a 10000 lbf thrust hybrid motor with a foil bearing LOx turbopump. 31st Al-AA/SAE/ASME/ASEE Joint Propulsion Conference and Exhibit, California, USA, July 10-12, 1995: AIAA-95-2941.

[51] J M Stoltzfus, J Dees, A Gu, et al. Material compatibility evaluation for liquid oxygen turbopump fluid foil bearing. 28th AIAA/SAE/ASME/ASEE Joint Propulsion Conference and Exhibit, Tennessee, USA, July 6-8, 1992: AIAA-92-3403.

[52] A Gu. Cryogenic foil bearing turbopumps. 32nd Aerospace Science Meeting \& Exhibit, Nevada, USA, January 10-13, 1994: AIAA-94-0868.

[53] J P Girault. Implementation of active magnetic bearings on advanced rocket engine turbopumps. In: G Schweitzer. Magnetic bearings, Berlin: Springer, 1989: 199-210.

[54] Y Le, J J Sun, B C Han. Modeling and design of 3-DOF magnetic bearing for high-speed motor including eddy-current effects and leakage effects. IEEE Transactions on Industrial Electronics, 2016, 63(6): 3656-3665.
[55] H Gao, L XXu, Y L Zhu. Unbalance vibratory displacement compensation for active magnetic bearings. Chinese Journal of Mechanical Engineering, 2013, 26(1): 95-103.

[56] S Eguchi, M Komori, T Okuhata. Prototype of self-sensing magnetic bearing for liquid pump. IEEJ Transactions on Industry Applications, 2007, 126(10): 1293-1297.

[57] J R Hull. Superconducting bearings. Superconductor Science and Technology, 2000, 13(2): R1-R15.

[58] J M Xu, C P Zhang, J L Wang, et al. Experimental investigations of novel compound bearing of superconducting magnetic field and hydrodynamic fluid field. IEEE Transactions on Applied Superconductivity, 2020, 30(1): 3600407 (7pp).

[59] J M Xu, R L Chen, H L Hong, et al. Static characteristics of high-temperature superconductor and hydrodynamic fluid-film compound bearing for rocket engine. IEEE Transactions on Applied Superconductivity, 2015, 25(6): 3601908 (8pp).

[60] J M Xu, XY Yuan, C P Zhang, et al. Dynamic characteristics of high-Tc superconductor and hydrodynamic fluid-film bearing for rocket engine. IEEE Transactions on Applied Superconductivity, 2016, 26(3): 3600505 (5pp).

[61] R L Chen, J M Xu, Y Y Wei, et al. Static and dynamic characteristics of superconducting magnetic force and hydrodynamic fluid film force compound bearings. Tribology, 2016, 36(5): 531-537. (in Chinese)

[62] Z M Zhao, F Ji, Y S Guan, et al. Method and experiments of temperature collaborative monitoring based on characteristics points for tilting pad bearings. Tribology International, 2017, 114: 77-83.

\section{Submit your manuscript to a SpringerOpen ${ }^{\circ}$ journal and benefit from:}

- Convenient online submission

- Rigorous peer review

- Open access: articles freely available online

- High visibility within the field

- Retaining the copyright to your article

Submit your next manuscript at $\boldsymbol{\Delta}$ springeropen.com 